\title{
A HOMOLOGIA ENTRE MAIS-VALIA E MAIS-DE-GOZAR NAS BASES DA SUBJETIVIDADE CAPITALISTA
}

DANIEL PEREIRA SILVA ${ }^{1 ; 2 ; 3}$; Orcid: https://orcid.org/0000-0002-4496-1650

${ }^{1}$ Universidade Estadual de Campinas (Unicamp), Programa de Pós-Graduação em Economia, Instituto de Economia, Campinas/SP, Brasil.

${ }^{2}$ Fundação Escola de Comércio Álvares Penteado (FECAP), Faculdade de Economia, São Paulo/SP, Brasil.

${ }^{3}$ Faculdade de Relações Internacionais, São Paulo/SP, Brasil.
RESUMO: Esse trabalho é motivado pela homologia estabelecida, por Lacan, entre a mais-valia e o mais-de-gozar. Buscamos evidenciar o embasamento dessa homologia e apontar seus efeitos nos fundamentos da subjetividade capitalista. Para tanto, combinamos a leitura do Seminário 16, de Lacan, a uma abordagem de $O$ capital, de Marx. Nesse processo, analisamos as articulações significantes do valor, do dinheiro e do fetiche na conformação da ordem simbólica do discurso capitalista.

Palavras-chave: mais-valia; mais-de-gozar; sujeito; capitalismo; fetiche.

Abstract: The homology between surplus-value and surplus-jouissance on the basis of the capitalist subjectiveness. This paper is an examination of the homology between surplus-value and surplus-jouissance, as set out by Lacan. We seek to demonstrate the basis of this homology and point out its effects on capitalist subjectivity. To this end, we combine a reading of Lacan's Seminar XVI with Marx's Capital. Throughout this process, we analyze how the articulation of signifiers, such as value, money and fetish, configures the symbolic order of capitalist discourse.

Keywords: surplus-value; surplus-jouissance; subject; capitalism; fetish.

DOI - http://dx.doi.org/10.1590/S1516-14982019001012

Todo o conteúdo deste periódico, exceto onde estiver identificado, está licenciado sob uma licença Creative Commons (cc by 4.0). 
Em sua perplexidade, pensam os nossos possuidores de mercadorias como Fausto. No começo era ação. Eles já agiram, portanto, antes de terem pensado. (MARX, 1988, p. 80).

Recorrerei a Marx, cujo dito tive muita dificuldade de não introduzir mais cedo, importunado que sou por ele há muito tempo, num campo em que, no entanto, ele fica perfeitamente em seu lugar. É de um nível homológico calcado em Marx que partirei para introduzir hoje o lugar em que temos de situar a função essencial do objeto $a$. (LACAN, 1968-1969/2008, p. 16).

Em O seminário, livro 16, Lacan associa de forma fundamental seu conceito de mais-de-gozar à mais-valia Ede Marx. Nesse ponto de seu ensino, o objeto a se constitui da apropriação da mais-valia, em sua lógica, pela psicanálise lacaniana. Na mais-valia, Lacan pespega no avesso a ideia de mais-de-gozar, de modo a fazêlos homólogos, não análogos, porque o objeto a e a mais-valia obedecem à mesma lógica. "Trata-se, com efeito, da mesma coisa" (LACAN, 1968-1969/2008, p. 44).

Realizada por Lacan, essa consubstanciação lógica entre dois elementos paradigmáticos não pode ter efeito simplesmente pontual para a abordagem dos corpos teóricos articulados. Antes, dizer que o objetocausa-de-desejo é a mesma coisa que a mais-valia implica também estabelecer a possibilidade de avançarmos na investigação de desencadeamentos homológicos no constructo psicanalítico lacaniano e na análise do capitalismo de Marx.

Essa homologia, vale dizer, deve se estender não só para considerações que derivam desses elementos paradigmáticos, mas também deve fazer questão sobre os fundamentos que possibilitam que, na mais-valia, Lacan possa prender, superpor a ideia de mais-de-gozar (LACAN, 1968-1969/2008, p. 29). O foco principal desse trabalho é, justamente, evidenciar, em Marx, o espaço para o embasamento dessa homologia e apontar seus efeitos nos fundamentos da subjetividade capitalista.

Nosso método consiste em abordar O capital (MARX, 1988), de modo a fazer sobressalente que o capitalismo consiste em um processo sucessivo de contenção e negação das formas que o possibilitam. A partir desse exercício, identificamos dois temas profícuos à psicanálise. O primeiro se desenvolve a partir da proposição de que esse processo lógico tem o caráter do que Lacan denomina de "ordem simbólica" ${ }^{1}$, ou seja, de constituição de uma ordenação significante a partir da qual os sujeitos se conformam. Segundo Lacan:

[...] a partir do momento em que se sustenta um discurso, o que surge são as leis da lógica, isto é, uma coerência refinada, ligada à natureza do que é chamado de articulação significante. [...] As leis dessa articulação, eis o que domina inicialmente o discurso. (LACAN, 1968-1969/2008, p, 79).

No que concerne, então, ao discurso capitalista, as "leis da lógica" estão postas quando os sujeitos assumem um lugar do qual tomam a palavra nesse laço social. Significa dizer que, do lugar do capitalismo, não é possível significar qualquer coisa, uma vez que seu espaço de sentido está condicionado, como veremos, tanto pelas leis da articulação simbólica que ocupam o lugar da verdade capitalista quanto pelo seu mais-degozar - o produto desse laço social:

Para demarcar bem as coisas, de fato, é preciso supor que no campo do Outro existe o mercado, que totaliza os méritos, os valores, que garante a organização das escolhas, das preferências, e que implica uma estrutura ordinal, ou até cardinal. (LACAN, 1968-1969/2008, p. 17 e 18, grifo nosso). ${ }^{2}$

\footnotetext{
1 “Que é uma ordem simbólica? É mais do que apenas uma lei, é também uma acumulação, ainda por cima numerada. É uma ordenação” (LACAN, 1968-1969/2008, p. 286).

${ }^{2}$ Lacan não havia ainda exposto sua teoria dos discursos quando dessa citação, no seminário De um Outro ao outro. Contundo, entendemos o que o termo "discurso" aqui empregado por Lacan já se situa, em termos lógicos, nos moldes propostos por essa teoria, que viria a ser apresentada pelo psicanalista francês no seminário do ano seguinte, chamado
} 
De outra forma, o significante mestre do capital esse significante vazio que representa a lei da lógica das diferenças entre os significantes no capitalismo - organiza o espaço simbólico no sentido de produzir um resto que é causa e resultante desse discurso: o mais-de-gozar capitalista, a mais-valia. Ademais, ao se referir a uma "estrutura ordinal, ou até cardinal", Lacan não só evidencia a importância da posição relativa dos significantes em suas diferenças, como também aponta para um limite cardinal dessa articulação: uma incomensurável mas efetiva magnitude de tais diferenças na organização simbólica ${ }^{3}$.

O segundo tema psicanalítico é o de que, por meio da psicanálise, podemos abordar como esses elementos contidos e negados subordinam a subjetividade no laço social capitalista. Há, como apontado nesse trabalho, diversos postulados subentendidos no capitalismo e que, porque incógnitos (ou incognoscíveis), se põem a produzir sobre os sujeitos. Ora, essa é exatamente uma das definições de "inconsciente" proposta por Lacan no Seminário 16: "Uma regra de pensamento que tem de se assegurar do não-pensamento como aquilo que pode ser sua causa: é com isso que nós nos confrontamos ao usar a ideia de inconsciente" (LACAN, 19681969/2008, p. 13).

O que nos faz saliente é que essa estrutura de pensamento inconsciente "tem de se assegurar do nãopensamento", ou seja, o ocultamento da estrutura lógica do capital, esse processo de contenção e negação, é condição para a existência daquilo que ele produz. Logo, nos faz questão, aqui, os fundamentos dessa produção obscena e de que modo ela se articula para significar a falta que incita à repetição, aos sintomas, ao gozo do discurso capitalista.

Com esse intuito, partimos do conceito de valor de uso da mercadoria e, por meio de sucessivos movimentos lógicos, alcançamos o fetiche, elemento que encerra o primeiro capítulo de $O$ capital e que traduz a condição de existência da organização social capitalista. Daí, nos estendemos nas concepções dinâmicas dessa existência, adentrando na forma capital, o valor que se valoriza. Nesse ponto, a concepção da mais-valia e sua homologia com o objeto $a$ nos proporcionam vislumbrar a falta fundamental que motiva o capital e o "falta-a-ser" que esse discurso produz.

\section{A TROCA CAPITALISTA E A INDIFERENÇA POR TRÁS DA IGUALDADE}

Nos primeiros parágrafos de $O$ capital, Marx busca estabelecer um suporte para a sua análise do capitalismo. Como suporte, queremos dizer o conceito de algo físico, não subjetivo. Algo externo às pessoas e, no limite, independente delas. Tal suporte é o conceito de "valor de uso", conceito este que aparece diretamente ligado ao propósito inicial do autor, isto é, a análise da mercadoria:

A mercadoria é, antes de tudo, um objeto externo, uma coisa a qual pelas suas propriedades satisfaz necessidades humanas de qualquer espécie. A natureza dessas necessidades, se elas se originam do estômago ou da fantasia, não altera nada na coisa. (MARX, 1988, p. 45).

Antes de tudo, a relação dos homens com os bens entre eles, aqueles que socialmente se fazem mercadorias é uma relação de uso, que parte de determinados aspectos do objeto. Segundo Marx, "a utilidade de uma coisa faz dela um valor de uso" (MARX, 1988, p.45). Significa dizer que o "valor" revestido de "uso" não possui caráter quantitativo, no sentido que não expressa uma medida de valia. Isso sim, o valor de uso é binário. Algo tem, ou não, valor de uso. Nessa acepção, esse conceito pode ser substituído, sem

O avesso da psicanálise (LACAN, 1969-1970/1992). Nesse sentido, o presente trabalho trata das bases do que viria a sustentar o discurso capitalista.

${ }^{3}$ Lacan faz uma clara alusão à teoria do valor utilidade da ortodoxia econômica, segundo a qual os agentes, dadas as suas preferências, atuam por meio de escolhas com a finalidade de maximizar seu bem-estar. Na segunda metade do século XIX, essa teoria supunha que a utilidade de um bem, mesmo que subjetiva, poderia ser mensurável, concebendo o que se denomina por utilidade cardinal. Contudo, o avanço da matematização da economia ressaltou a inviabilidade de se estabelecer uma medida absoluta de utilidade, de modo que essa concepção foi substituída pela de utilidade ordinal, no começo do século XX (ver SCHUMPETER, 1954). 
maiores prejuízos semânticos, pelo termo "serventia". Esse é o apoio concreto que Marx apresenta, de partida, em sua análise.

“Descobrir esses diversos aspectos e, portanto, os múltiplos modos de usar as coisas é um ato histórico" (idem). Historicamente, as pessoas subjugam os objetos, e o fazem, como Marx menciona metonimicamente, movidas pelo "estômago" ou pela "fantasia". Nesse sentido, quando tratamos de "mercadoria" isso é, de um ato histórico, nos referimos ao fruto do trabalho de alguém, cuja finalidade é ser trocado com outrem. Não servindo como uso àquele que a produz, a serventia da mercadoria não reside, originalmente, sob seu corpo. Quer dizer que, em essência, não é o uso que determina o valor da mercadoria. Esse valor só pode ser expresso pela possibilidade da realização da coisa em mercadoria, ou seja, por sua capacidade de ser trocada. Marx denomina essa espécie de valia como valor de troca.

Por conseguinte, o valor de troca não pode ser concebido como um atributo físico de um bem, mas, sim, como uma condição lógica da mercadoria. Note-se: essa lógica só pode ser possibilitada pela introdução de caracteres subjetivos, porque atribuir um valor de troca a um bem significa compreender uma relação social entre uma pessoa e um terceiro, relação essa que envolve o desejo mútuo e coincidente pelo objeto alheio. Conquanto, mesmo sendo fruto de uma relação social, o valor de troca está condicionado àquele concreto valor de uso, pois as pessoas efetuam o câmbio de mercadorias com a intenção de fazerem uso do objeto do outro. Em outras palavras: o valor de troca tem como base e possibilidade o valor de uso.

Ocorre, todavia, que o valor de troca é uma circunstância social implicada de subjetividade e que se realiza por um movimento essencial: a abstração. Se, em termos concretos, a avaliação de um objeto por parte de uma pessoa só pode se efetuar em termos da utilidade (ou não) das propriedades físicas da coisa, então, avaliar um objeto pela possibilidade de ser volição de outrem, que coincidentemente detém aquilo que é desejado, só pode ser um recurso à abstração. Mais do que isso, é importante destacar que essa abstração se realiza pela negação imediata do valor de uso do fruto do próprio trabalho. Significa dizer que a mercadoria nega, ao mesmo tempo em que contém, aquele suporte físico da relação entre as pessoas e os objetos.

O que se torna flagrante na abstração de valores de uso em valores de troca é a conversão de um caráter qualitativo, noutro quantitativo. Entretanto, o valor de uso ser a essência do valor de troca implica que esse último deveria, qual o primeiro, ser de caráter qualitativo. Ora, se algo tem (ou não) valor de uso, então pode ter (ou não) valor de troca. Porém, o que se observa no ato social da troca capitalista é que ele pressupõe termos pelos quais essa troca se efetiva, isto é, uma determinada quantidade de um bem é trocada por uma determinada quantidade de outro bem. A extensão da negação do uso da mercadoria, então, possibilita a subsequente negação de seu caráter qualitativo, em prol da elevação simbólica de referências quantitativas.

E quais seriam essas referências? Afinal, como coisas qualitativamente diferentes podem ser equiparadas e trocadas no capitalismo? O que é comum em suas diferenças? Certo, a mercadoria só pode se conceber quando a história engendrou uma organização social de extrema divisão do trabalho, em que os trabalhadores estão desprovidos dos meios de produção e se submetem ao trabalho assalariado como forma de obterem os recursos necessários à subsistência. "Deixando de lado então o valor de uso dos corpos das mercadorias, resta a elas apenas uma propriedade, que é a de serem produtos do trabalho" (MARX, 1988, p. 47). O que as mercadorias possuem em comum, portanto, além do qualitativo valor de uso, é o fato de terem sido geradas pelo trabalho de alguém. Em efeito, deve aí residir a possibilidade de atribuir a elas algum valor quantitativo que as permitam ser comparáveis: na quantidade de tempo despendido em sua produção.

Mais do que isso, nesses moldes históricos, a condição de existir do sujeito está atrelada à conjuntura do trabalho heterônomo. Antes de qualquer coisa, simbolicamente, o sujeito somente se concebe quando se sujeita a transformar sua lida em mercadoria, em força de trabalho. Nesse sentido, o requisito de "assalariado" ancora "às condições mais elementares e menos desenvolvidas de sua própria espécie: aquelas condições que dizem respeito a sua sobrevivência e reprodução física" (SILVEIRA, 1989, p. 45). No capitalismo: "o trabalhador se torna servo do seu objeto (...) para que possa existir primeiro como trabalhador e, segundo, como sujeito 
físico" (MARX, 1989, p. 152). Significa que o trabalho em nome do outro ocupa posição excelente para o sujeito na cadeia de significação de si. Na estrutura ordinal e cardinal desse laço social, "humano trabalhador" se arranja como "empregado então humano".

Temos, como consequência, o seguinte enunciado: uma mercadoria é trocável por outra porque as pessoas a criaram para tanto, e a sua criação se deu a partir do dispêndio de tempo em trabalho heterônomo. Ora, quanto maior o tempo despendido na lida, maior a quantidade de bens alheios que se almeja comandar. Então, o valor de troca de uma mercadoria está correlacionado ao tempo dedicado à sua elaboração.

Conquanto o tempo de trabalho individual seja a possibilidade desse valor de troca, ele não resolve a desconformidade, uma vez que mesmo o trabalho existe em qualidades distintas. Como reduzir a uma unidade comum "tempo de trabalho despendido" se tão diferentes podem ser as formas de despender o tempo trabalhando? Como comparar o tempo de trabalho de um estivador ao de um cozinheiro? Se a incongruência não reside no "tempo", indubitavelmente ela se realiza no "trabalho". Quantizar e equiparar essas atividades só pode ser pela negação da disparidade, isto é, negligenciando a pessoa que exerce a atividade. Segundo Marx:

\begin{abstract}
Se abstrairmos o seu valor de uso [de um bem], abstraímos também os componentes e formas corpóreas que fazem dele valor de uso. Deixa já de ser mesa ou cadeira ou fio ou qualquer outra coisa útil. Todas as quantidades sensoriais se apagaram. Também já não é o produto do trabalho do marceneiro ou do pedreiro ou do fiandeiro ou de qualquer outro trabalho produtivo determinado. Ao desaparecer o caráter útil dos produtos, desaparece o caráter útil dos trabalhos neles representados, e desaparecem também, portanto, as diferentes formas concretas desses trabalhos, que deixam de diferenciar-se um do outro para reduzir-se em sua totalidade a igual trabalho humano, a trabalho humano abstrato. (MARX, 1988, p. 47).
\end{abstract}

A redução do tempo de trabalho individual a um tempo de trabalho abstrato faz com que a relação social construída em torno do modo de produção capitalista se afaste ainda mais daquele suporte ideal do vínculo entre as pessoas e os objetos: o valor de uso. Ademais, da mesma forma que o valor de troca contém e nega o valor de uso, também o tempo de trabalho abstrato tem a sua possibilidade no tempo de trabalho individual, embora o negue na imposição simbólica de um tempo laboral social e sem feitio.

Nas cadeias de significação do laço social capitalista, esse movimento de abstração tem de ser sustentado por uma articulação de significantes que permita a troca de bens desiguais produzidos por trabalhos e trabalhadores desiguais. Deve haver, para tanto, uma denegação dos significantes que expressem essas inescapáveis diferenças e, dessa forma, se possa conceber uma realidade indiferente quanto à qualidade das mercadorias trocadas, dos trabalhos que geram essas mercadorias e, consequentemente, quanto aos sujeitos que as produzem.

Entra em crise o registro da diferença dos homens, ao passo que a indiferença se difunde pela subjetividade social. Suas raízes de legitimação econômica estão diretamente ligadas à possibilidade lógica da troca de desiguais. Queremos dizer que, se o trabalho social abstrato reduz qualquer tipo de atividade laboral a uma escala amorfa e qualitativamente indiferente de esforço, então se tem diminuída simbolicamente a possibilidade de identificação de si e do outro como agentes fundamentalmente díspares, historicamente determinados e socialmente dependentes.

Mais do que isso, no registro imaginário capitalista, a negligência da diferença é chamada de "igualdade". Quer dizer que a "in" diferença é imaginarizada como "não" diferença. Ora, se, para assumir um valor de troca quantitativo, necessitamos conceber um (também quantitativo) tempo de trabalho social, abstrato e anônimo, o que dizer sobre os sujeitos, suportes dessa construção histórica? Que eles só podem ser comparados quantitativamente e nos termos de seus valores de troca. Que em termos qualitativos eles são igualmente implicados na lógica desse laço social. A igualdade capitalista é, assim, uma representação da indiferença. 
Ademais, se a indiferença capitalista diz não importarem os processos históricos e sociais que geraram sujeitos fundamentalmente singulares, então compreende-se a possibilidade simbólica do princípio da livre iniciativa. De que outra forma poderíamos conceber que alguém possa ser livre para iniciar? 0 que mais subentende a livre iniciativa além da fantasia de que o tempo começa em qualquer momento; de que podemos, em qualquer instante, "des"envolver? Não é, exatamente, o prejuízo simbólico do tempo histórico e a elevação significante de um tempo escalar?

Enquanto as pessoas se fazem iguais e livres em seu imaginário mercadológico, o que se apresentam na narrativa que se desenvolve na outra cena, ou seja, no inconsciente, são sujeitos que escorregam por significantes de indiferença, significantes esses que são condições sine qua non da organização social capitalista.

\section{O VALOR E O ESTRANHAMENTO DOS SUJEITOS: A MERCADORIA COMO SIGNIFICANTE}

Na sequência do constructo marxiano, temos que o valor de troca, como o próprio termo já indica, só pode se manifestar na troca, no embate entre duas mercadorias. Significa dizer que a mercadoria A tem seu valor manifestado socialmente no confronto com a mercadoria $B$, de acordo com a quantidade da mercadoria B que ela alcança cambiar.

Logo, não basta eclipsar os seus fundamentos lógicos e históricos: a mercadoria relativa (A) só se nomeia em outra mercadoria, sua equivalente (B), quando um objeto $B$, que possui de físico o seu valor de uso, empresta seu corpo para expressar o valor do objeto $A$. Esse objeto $A$ tem seu corpo transformado pela equivalência a B; ele se torna espelho do valor de B. Em outras palavras, aquela mercadoria $A$ só se faz efetivamente mercadoria quando houver uma mercadoria B que, por seu valor de uso, lhe empreste a (equi)valência - as várias valências de seu corpo.

Simbolicamente, a mercadoria carrega para seu possuidor, então, a potência de se representar em um desdobramento infindável de produtos, uma vez que seu significado é um escorregar simbólico por uma cadeia de outros bens que, por força do capital, também só podem ser mercadorias. A homologia com a estrutura simbólica lacaniana é flagrante. A existência de um bem enquanto mercadoria estabelece que ele seja um significante determinado por uma cadeia interminável de outros significantes. De fato, por ser um não-valor-de-uso, a essência da mercadoria reside na latência de ser diferente de si mesma. Ora, "nada fundamenta a função do significante senão ele ser uma diferença absoluta. É somente através daquilo em que os outros diferem dele que o significante se sustenta" (LACAN, 1968-1969/2008, p. 192).

Dessa forma, a mercadoria avança em emancipar-se, simbolicamente, do humano. Porque, enquanto mercadoria, enquanto bem para troca, ela nega o trabalho que a produziu. "Desaparece a relação eventual de dois donos individuais de mercadorias" (MARX, 1988, p. 65). Ela se faz, assim, estranha. Ela não é objeto do humano para o humano, é uma coisa, forma abstrata dotada de autonomia. Fundamentalmente, a mercadoria carrega em si a necessidade simbólica do estranhamento do sujeito com o produto de seu trabalho e, logo, o estranhamento do próprio trabalho e do tempo de vida despendido na lida.

Todavia, o movimento de abstração capitalista é ainda mais intenso. Se à mercadoria não cabe outra coisa senão a troca, de modo que a troca está nela implícita antes mesmo do ato de trocar, então ela contém e nega inclusive o caráter "de troca" de seu valor. O que se sobressai na relação mercantil é que A se relaciona com B como se já carregasse intrinsecamente valor de troca. A propriedade de ser equivalente parece pertencer-lhe até mesmo fora de sua relação com B, no mesmo nível das propriedades físicas que constituem seu valor de uso (ŽIŽEK, 1996, p. 14). A mercadoria, então, institui o valor. Seu valor, o valor, inicia nela a sua significação social. “Quando, no início desse capítulo, para seguir a maneira ordinária de falar, havíamos dito: A mercadoria é valor de uso e valor de troca, isso era, a rigor, falso. A mercadoria é valor de uso ou objeto de uso e 'valor'” (MARX, 1988, p. 62). 
Pois que o impacto dessa lógica significante é a incontestável e volumosa presença de referências mercadológicas na significação de valor na sociedade capitalista, de modo que a avaliação de si, dos objetos e de terceiros tende escorregar, antes de mais nada, por significantes materiais, como se todos fôssemos uma espécie de reflexo da mercadoria.

Como essência da avaliação social e como meio de significação, a mercadoria implica um sujeito iminentemente reificado. $E$, mais do que uma reificação pessoal, o próprio laço social, que envolve a troca de produtos do trabalho humano, assume a inclinação assintótica de uma relação entre coisas. Esses sujeitos, suportes da organização social capitalista, acabam potencialmente representados de uma mercadoria para outra mercadoria, de modo que são avaliados no infinito da forma equivalente do valor mercadológico.

\section{O DINHEIRO COMO TUDO E O FETICHE COMO MODO: UMA SOLUÇÃO DE COMPROMISSO OBSCENA}

A despeito dessa articulação lógica de significantes que enunciaria a base e a possibilidade da troca de desiguais na sociedade capitalista, o que se observa como manifesto no processo de intercâmbio de mercadorias é que os termos pelos quais a troca se efetiva não são um tipo de contabilização do tempo de trabalho socialmente necessário à produção. Isso sim, as mercadorias se nomeiam por cifras outras e que parecem se definir às costas dos produtores: elas recebem um independente nome monetário.

A denominação de uma coisa é totalmente extrínseca à sua natureza. Eu não sei nada sobre um homem sabendo que seu nome é Jacobus. Do mesmo modo, desaparece nos nomes monetários libra, táler, franco, ducado etc. qualquer vestígio da relação de valor. [...] Por outro lado, é necessário que o valor, em contraste com os coloridos corpos do mundo das mercadorias, evolua para essa forma reificada sem sentido próprio, mas também simplesmente social. (MARX, 1988, p. 90-91).

O dinheiro é o equivalente geral das trocas e, enquanto tal, expande a relação social das mercadorias. Ele passa a ser a expressão da avaliação mercantil, não só por quantificar o valor mercadológico, mas por se tornar, na troca, a condição de realização tanto da mercadoria, quanto do trabalho e do trabalhador. O que mais resta para a moeda se tornar o signo excelente do valor? E, todavia, na medida que é um signo, o dinheiro obnubila, denega toda a teia lógica de articulação significante que propicia o laço social que o suporta. "É exatamente essa forma acabada - a forma dinheiro - do mundo das mercadorias que objetivamente vela, em vez de revelar, o caráter social dos trabalhos privados e, portanto, as relações sociais entre os produtores privados" (ibidem, p 73).

Ainda mais além, por ser esse equivalente geral das trocas, a moeda encarna a possibilidade de ser tudo, de modo que assume posição e magnitude absurdas no registro simbólico capitalista. Seus determinantes lógicos e sua liquidez dão a possibilidade de que o sujeito esteja excitado a imaginarizar a reposição do objeto a. Se o objeto $a$ é o elemento lógico que implica em uma falta inescapável e, dela, um desejo constante, então temos no dinheiro uma solução de compromisso contra o desejo. Ora, se o desejo deseja o infinito, o dinheiro perverte o infinito, traduzindo-o como "todas as mercadorias".

Desse modo, para os sujeitos que se fazem como efeito desse laço social, ter o dinheiro é ter, no limite, o infinito. A sociedade capitalista empreende repor o objeto a no universo simbólico e imaginá-lo como

moeda. É por isso que o desenvolvimento do capital significa a intensificação da perversão dos sujeitos. A perversão é, justamente, "a restauração como que primordial, a restituição do a ao campo do A" (LACAN, 1968-1969/2008, p. 283). Em outras palavras, o sujeito perverso é aquele que tem, inconscientemente, barrada a sua possibilidade de resolução do desejo, mas que "toma o cuidado de suprir a falha do Outro" (ibidem, p. 257), se consagrando a tapar o furo estrutural do significante.

Por esses meios, se Marx inicia o primeiro capítulo de O capital apoiado na concepção de valor de uso como algo físico e, no limite, desumanizado, ele encerra esse capítulo apresentando o resultado da introdução de um sujeito vale dizer, histórico na lógica subjetiva da organização social capitalista: o fetiche. O fetiche é, 
justamente, o enredo dessa solução de compromisso que sustenta a alienação dos sujeitos no capital. Ele é a forma de existência manifesta do capitalismo, seu modus operandi.

Quer dizer que, se a troca capitalista é uma manifestação desencadeada por condições que escapam aos trocadores, então seu fetichismo concerne no fato da troca ser tomada como uma forma de relação entre os bens e o dinheiro, em vez de um modo de relação social. Como ressalta Žižek, "o aspecto essencial do fetichismo da mercadoria não consiste na famosa substituição dos homens por coisas [...], mas, antes, num certo desconhecimento da relação entre uma rede estruturada e um de seus elementos [o dinheiro]" (ŽlŽEK, 1996, p. 13 e 14).

Ademais, a moeda é a encarnação fetichista da riqueza, não porque as pessoas desconhecem o fato de que ela é apenas uma fidúcia social que nada vale além da crença. Não. Efetivamente elas o sabem, mas... fingem que não sabem. Por isso, o fetiche capitalista é uma forma de perversão. Ele consiste, exatamente, em eleger algo para pôr no lugar de um significante barrado no inconsciente do sujeito. No entanto, na perversão fetichista, se todo o processo de ocultação de um determinado significante é omitido ao sujeito, não lhe é omitida uma certa estranheza da posição que o objeto substituto assume, de modo que é por isso a sua máxima: "eu sei... mas finjo eu não sei" (FREUD, 1927/1996). O dinheiro, nesse sentido, é exatamente isso, se bem que expandido largamente na sociedade. Por isso, Lacan afirma que a moeda é o fetiche por excelência (LACAN, 1968-1969/2008, p. 277).

Ora, significa dizer que o estatuto do fetiche capitalista não é da ordem do saber, mas da ordem do agir. O que as pessoas não sabem é que a sua realidade social é guiada por uma ilusão, uma inversão fetichista (ŽIŽEK, 1996, p. 22). Ou seja, fingindo não saber, os sujeitos reproduzem em seus atos o que, de fato, não sabem: $\mathrm{o}$ arcabouço significante que possibilita o capital.

Simbolicamente, então, o laço social capitalista concebe um modo de ordenar e valorar cadeias de significantes e construir uma narrativa, descrevendo os sujeitos, os objetos e os terceiros. Trata-se de "um processo de desenvolvimento e deformação do poder da capacidade de significar que os próprios homens foram criando no desenvolvimento histórico e que, no final, implica uma transformação, uma metamorfose, uma formação de subjetividade" (ROZITCHNER, 1989 p. 124). Mais do que isso, o que Marx evidenciou na formulação do fetiche capitalista é que a denegação das condições lógicas da existência do capital é fundamental para que a organização desse laço social se mantenha e se reproduza.

\section{A MAIS-VALIA COMO MAIS DE GOZAR: A PRODUÇÃO E O MOTIVO DE UM GOZO}

Ainda não alcançamos estabelecer os fundamentos e as decorrências da homologia entre mais-valia e mais-de-gozar na formação da subjetividade capitalista. Há algo que falta às formas mercadoria e dinheiro para que elas forneçam aos sujeitos um caráter específico de repetição e, logo, de gozo. Encontramos a implicação lógica dessa falta quando Marx institui a forma capital:

Abstraiamos o conteúdo material da circulação das mercadorias, o intercâmbio dos diferentes valores de uso, e consideremos apenas as formas econômicas engendradas por esse processo, então encontraremos como seu produto último o dinheiro. Esse produto último da circulação de mercadorias é a primeira forma de aparição do capital. (MARX, 1988, p. 121).

Marx, assim, inicia explicitamente seu tratamento do capital. Para o autor, o capital é o signo dinheiro (e suas metamorfoses) em processo de valorização. Ele é o início e o fim da ampliação incessante de valor monetário (MARX, 1988, p. 123). Ora, o motivo indutor desse processo é algo sempre faltante, um elemento nunca suficiente e que sempre incita à insaciedade, a querer gozar de um valor além: a mais-valia.

Concebida pela diferença entre o valor gerado e o valor pago pela força de trabalho, a mais-valia se constitui como um excedente negativo. Excedente, porque representa o valor criado pelo processo produtivo e apropriado pelo capitalista. Negativo, porque esse mais-valor só existe enquanto tal quando, renunciado, 
comanda uma nova série de diferenças significantes e gera uma nova apropriação de valor. Trata-se de um processo infinito de excedente e renúncia, de acréscimos pela perda:

Um sujeito é aquilo que pode ser representado de um significante para outro significante. Não será isso calcado no fato de que, no que Marx decifrou, isto é, a realidade econômica, o sujeito do valor de troca é representado perante o valor de uso? É essa brecha que se produz e cai a mais valia. Em nosso nível, só importa essa perda. Já não idêntico a si mesmo, daí por diante o sujeito não goza mais. Perde-se alguma coisa que se chama mais-de-gozar. Ele é estritamente correlato à entrada em jogo do que determina, a partir de então, tudo o que acontece com o pensamento. (LACAN, 1968-1969/2008, p. 21).

Nesse movimento de diferenciação significante, de negação e contenção das formas, os valores de uso se tornam valores de troca, transformando o trabalho individual em trabalho social abstrato; os valores de troca se tornam o valor, cujo signo cabal é o dinheiro; o mais dinheiro, finalmente, se converte no fim último da existência capitalista. E o que permite essa série fetichista de diferenças é a existência de uma falta inerente, que coopta a organização significante desse laço social: a mais-valia. Enquanto mais-de-gozar, a mais-valia é "uma função da renúncia ao gozo sobre efeito do discurso. Isso que dá lugar ao objeto $a$ " (LACAN, 2008, p. 19).

O sujeito, seja qual for a forma em que se produza em sua presença, não pode reunir-se em seu representante de significante sem que se produza, na identidade, uma perda, propriamente chamada de objeto a. É isso que é designado pela teoria freudiana concernente à repetição. (...) Nada pode produzir-se aí sem que um objeto seja perdido. (LACAN. 2008, p. 21).

Essa lógica nos conduz ao que Tomšič (2015, p. 117) destacou como sendo o mediador conceitual da homologia entre a mais-valia e o mais-de-gozar: o Lustgewinn, de Freud. Como marca inconsciente do chiste, o termo Lustgewinn define um prazer excedente, como ganho de prazer, algo que se estabelece para além da utilidade, que sobra e decai como resto ${ }^{4}$. É exatamente esse excedente que Lacan reconhece na mais-valia. Segundo Lacan, a essência da mais-valia é revelada quando Marx "apontou que o personagem fantástico com quem ele se defrontava, o capitalista, ria” (LACAN, 1968-1969/2008, p. 63, grifo nosso):

Refiro-me à conjunção do riso com a função radicalmente eludida da mais-valia, da qual já indiquei suficientemente a relação com a elisão característica que é constitutiva do objeto a (idem).

Com efeito, a mais-valia e o mais-de-gozar são mesma coisa. Se o objeto $a$ é aquele que produz a falta que funda o sujeito do desejo, o "falta-a-ser", então a mais-valia é o mesmo. Ela exerce a função do mais-degozar na articulação simbólica historicamente estabelecida no discurso capitalista, ocupando, nesse discurso, o lugar de uma produção negativa, uma perda que incessantemente acumula. A mais-valia é o motivo do discurso capitalista, no qual se sustenta a formação simbólica e imaginária dos sujeitos que são efeitos desse laço. "A mais-valia, portanto, é fruto dos meios de articulação que constituem o discurso capitalista. É o que resulta da lógica capitalista" (LACAN, 1968-1969/2008, p. 37).

Significa dizer que as condições estabelecidas historicamente fazem com que o capital somente se reproduza enquanto a mais-valia sintomatizada pelo gozo fetichista da moeda e, logo, possibilitada por toda a teia inconsciente que compõe a verdade da articulação do sujeito no laço social for o mais-de-gozar. Por esses meios, a mais-valia é a força movente, dinâmica, do capitalismo. Ela é o que faz do capital um processo de acumulação sem limites. "Por isso o movimento do Capital é insaciável” (MARX, 1988, p. 125).

${ }^{4}$ Segundo Tomšič (2015, p. 117), essa inutilidade do excesso que direciona o conceito de Lust (prazer) em Freud (1905/1996) faz com que Lacan traduza esse último termo alemão como jouissance (gozo) ao invés de plaisir (prazer). O plus-de-jouir (mais-de-gozar) é devolvido ao alemão como Mehrlust (LACAN, 2008, p. 29-30), forma essa que carrega a mais-valia (Mehwert) e o excedente não útil de prazer (Lustgewinn). 
No que respeita aos suportes dessas relações sociais, o capitalista, possuidor da forma capital e "portador consciente desse movimento" (MARX, 1988, p. 125), é o vetor personificado e dotado da consciência e da vontade do capital.

Sua pessoa, ou melhor, seu bolso, é o ponto de partida e o ponto de retorno do dinheiro. O conteúdo objetivo daquela circulação - a valorização do valor - é a sua meta subjetiva, e só enquanto a apropriação crescente da riqueza abstrata é o único motivo indutor de suas operações, ele funciona como capitalista (...). (idem).

Percebam, o capitalista é dotado da consciência da vontade do capital. Ele sabe que quer mais valor. Sabe que a sua condição de capitalista requer isso. Ele sabe do bônus que essa posição lhe proporciona. E, tomado desse saber, ele assume a sua autonomia para empreender livremente o que lhe é racionalmente legado. Contudo, esse saber, autonomia, liberdade e racionalidade são completamente condicionados ao arcabouço inconsciente, abstrato e contraditório do capital. O capitalista é suporte do capital e dos valores fetichistas que racionaliza na sociedade.

As demais posições econômicas, como a do trabalhador e a do consumidor, não gozam da realização continuada de mais-valia. Isso sim, imersos nas condições significantes impostas por esse mais-de-gozar, os demais sujeitos do capital têm suas possibilidades de gozo cerceadas e subsidiadas pela mais-valia. O gozo do consumo e o gozo do trabalho são exemplares cada vez mais evidentes do esvaziamento de sentido imaginário e reificação de suas funções para o sujeito.

Especificamente no que concerne aos trabalhadores, aqueles que não possuem as condições de incorporar o capital, a maioria despojada dos meios de produção, na sociedade de extrema divisão do trabalho e de intensa interdependência pessoal, resta reificar sua corporalidade viva e suas faculdades espirituais, transformando um pedaço do tempo de sua vida em mercadoria para vendê-la como força de trabalho:

Ora, articulado dessa maneira, esse discurso acarreta uma certa posição do Eu no sistema. Quando esse Eu está no lugar do trabalhador, o que constitui o caso cada vez mais geral, a citada posição comporta uma reivindicação concernente à frustração, entre aspas, do trabalhador. (LACAN, 1968-1969/2008, p. 37).

No tempo, o processo, por vezes subsumido, de sobrevivência (que possibilita o trabalhador), amalgamado ao de lucro (que possibilita o capitalista), automatiza de forma dinâmica e ética "um monstro animado que começa a 'trabalhar' como se tivesse amor no corpo" (MARX, 1988, p. 154).

\section{CONCLUSÃO}

No percurso teórico empreendido nesse trabalho, buscamos embasar a homologia entre a mais-valia e o mais-de-gozar, bem como avançar nos efeitos dessa homologia sobre a subjetividade capitalista. Para tanto, caracterizamos o processo lógico que possibilita o capital como uma ordem simbólica, ou seja, uma articulação significante ordinal e cardinal no campo do Outro. A partir desse exercício, buscamos mostrar que as leis da lógica dessa articulação implicam em um movimento contínuo de contenção e negação de significantes, construindo um discurso do qual partem as formas de subjetivação dos sujeitos desse laço social.

Nesse sentido, a verdade do capital, seu significante mestre, é constituída do comando das diferenças entre os significantes (1) valor de uso e valor de troca, (2) valor de troca e valor, (3) valor e dinheiro e (4) dinheiro e capital. Essa série de diferenças domina o espaço lógico de significação do discurso capitalista, implicando na homologia entre significante e mercadoria, pervertendo o dinheiro como um suprimento fetichista da falta do Outro e produzindo a mais-valia, enquanto mais-de-gozar, como uma função da renúncia do gozo, causa e fruto do discurso.

Mais do que isso, a pervasividade do capital também configura um avançar simbólico e imaginário da lógica que o possibilita, no que concerne ao saber e aos sujeitos que são efeitos desse discurso. Significa dizer que (1) a elevação dos caracteres quantitativos em relação aos qualitativos, (2) o estranhamento do sujeito com o fruto de seu trabalho, (3) o condicionamento do sentido do sujeito ao trabalho heterônomo, (4) a 
indiferença para com o outro, (5) a prejuízo do tempo histórico em favor de um tempo escalar, (6) a autonomização da mercadoria e (7) o seu posicionamento excelente na nomeação dos sujeitos, bem como (8) o estabelecimento do dinheiro como signo do valor social, são preposições lógicas que se intensificam na medida em que o capitalismo se reproduz e que produzem, amiúde, os sujeitos que sustentam esse laço social.

Nesse sentido, o capital pela contenção e negação de sua materialidade, da singularidade do trabalho, da especificidade histórica que o concebeu, das suas condições sociais, políticas e lógicas produz uma narrativa simbólica particular, na qual a mercadoria, o valor, o dinheiro e os sujeitados ao capital se tornam entes transcendentais, pertencentes a uma "ordem natural", como entende a economia política clássica. Partimos dessas concepções, dessa narrativa, como se fosse o racional, e chamamos o desenrolar "ótimo" dessas condições de racionalidade, quando, na verdade, estamos tratando de categorias postas pela história, possibilitadas pela denegação e reproduzidas fetichisticamente. "Em sua perplexidade, pensam os nossos possuidores de mercadorias como Fausto. No começo era ação. Eles já agiram, portanto, antes de terem pensado" (MARX, 1988, p. 80).

Recebido em: 9 de novembro de 2016, Aprovado em: 3 de julho de 2017.

\section{REFERENCIAS}

FREUD, S. Fetichismo (1927). Rio de Janeiro: Imago, 1996. P. 155-160. (Ed. standard brasileira das obras psicológicas completas de Sigmund Freud, 21)

Os chistes e sua relação com o inconsciente (1905). Rio de Janeiro: Imago, 1996. P. 17-219. (Ed. standard brasileira das obras psicológicas completas de Sigmund Freud, 8)

LACAN, J. De um Outro ao outro (1968-1969). Rio de Janeiro: Jorge Zahar, 2008. (O seminário, 16) O avesso da psicanálise (1969-1970). Rio de Janeiro: Jorge Zahar, 1992. (O seminário, 17)

MARX, K. O capital: crítica da economia política. v. 1-5. São Paulo: Nova Cultural, 1988. O trabalho alienado e superação positiva da auto-alienação humana. In: FERNANDES, F. (org.) Marx Engels. São Paulo: Ática, 1989.

ROZITCHNER, L. Marx e Freud: a cooperação e o corpo produtivo. A expropriação histórica dos poderes do corpo. In: SILVEIRA, P.; DORAY, B. (org.). Elementos para uma teoria marxista da subjetividade. São Paulo: Revistas dos tribunais, 1989.

SCHUMPETER, J. History of Economic Analysis. New York: Oxford University Press, 1954.

SILVEIRA, P. Da alienação ao fetichismo - formas de subjetivação e de objetivação. In: SILVEIRA, P.; DORAY, B. (org). Elementos para uma teoria marxista da subjetividade. São Paulo: Revistas dos tribunais, 1989.

TOMŠIČ, S. The capitalist unconscious: Marx and Lacan. Londres: Verso, 2015.

ŽIŽEK, S. Como Marx inventou o sintoma?. In: (org.) Um mapa da ideologia. Rio de Janeiro: Contraponto, 1996

\section{Daniel Pereira Silva}

Doutorando pelo Programa de Pós-Graduação em Economia, Instituto de Economia, Universidade Estadual de Campinas (Unicamp), Campinas/SP, Brasil

Professor da Faculdade de Economia Fundação Escola de Comércio Álvares Penteado (FECAP), e da Faculdade de Relações Internacionais, São Paulo/SP, Brasil. danielpsilva@hotmail.com 